\title{
Corrigendum: Importance of adhesins in virulence of Paracoccidioides spp.
}

\author{
Haroldo Cesar de Oliveira * \\ Laboratório de Micologia Clínica, Departamento de Análises Clínicas, Faculdade de Ciências Farmacêuticas, \\ UNESP-Universidade Estadual Paulista, Araraquara, Brazil
}

\section{OPEN ACCESS}

Edited and reviewed by: Helio K. Takahashi, Universidade Federal de Sao Paulo,

Brazil

${ }^{*}$ Correspondence: Haroldo Oliveira, haroldocdoliveira@gmail.com

Specialty section:

This article was submitted to Fungi and Their Interactions,

a section of the journal

Frontiers in Microbiology

Received: 16 April 2015

Accepted: 22 April 2015

Published: 05 May 2015

Citation:

Oliveira HC (2015) Corrigendum: Importance of adhesins in virulence of Paracoccidioides spp.

Front. Microbiol. 6:431. doi: 10.3389/fmicb.2015.00431
Keywords: virulence, adhesion, adhesins, Paracoccidioides lutzii, Paracoccidioides brasiliensis

\section{A corrigendum on}

Importance of adhesins in virulence of Paracoccidioides spp.

by Oliveira, H. C., Silva, J. F., Scorzoni, L., Marcos, C. M., Rossi, S. A., de Paula e Silva, A. C. A., et al. (2015). Front. Microbiol. 6:303. doi: 10.3389/fmicb.2015.00303

One of the funding sources was omitted from the Acknowledgments list. The corrected list is as follows. This work was supported by the Brazilian organizations Fundação de Apoio à Pesquisa do Estado de São Paulo (FAPESP) 2011/18038-9, Rede Nacional de Métodos Alternativos-Conselho Nacional de Desenvolvimento Científico e Tecnológico (RENAMA-CNPq) 403586/2012-7 and Programa de Apoio ao Desenvolvimento Científico da Faculdade de Ciências Farmacêuticas da UNESP (PADC/FCF). We thank Daniella Sayuri Yamazaki for support with the animal experiment and Dr. Isabel Cristiane da Silva for all the support with A549 pneumocytes culture.

Conflict of Interest Statement: The author declares that the research was conducted in the absence of any commercial or financial relationships that could be construed as a potential conflict of interest.

Copyright $\odot 2015$ Oliveira. This is an open-access article distributed under the terms of the Creative Commons Attribution License (CC BY). The use, distribution or reproduction in other forums is permitted, provided the original author(s) or licensor are credited and that the original publication in this journal is cited, in accordance with accepted academic practice. No use, distribution or reproduction is permitted which does not comply with these terms. 